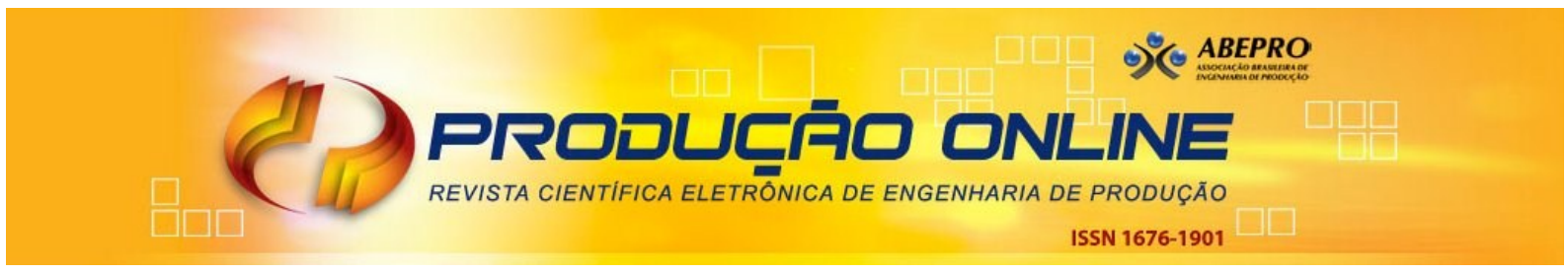

\title{
ASPECTOS DA GESTÃO DE DESIGN ABORDADOS EM DISSERTAÇÕES E TESES NO BRASIL: UMA REVISÃO SISTEMÁTICA
}

\section{DESIGN MANAGEMENT ASPECTS IN BRAZILIAN DISSERTATIONS AND THESES: A SYSTEMATIC REVIEW}

\author{
Claudia de Souza Libanio* E-mail: clasl@terra.com.br \\ Fernando Gonçalves Amaral* E-mail: amaral@producao.ufrgs.br \\ *Universidade Federal do Rio Grande do Sul - UFRGS, Porto Alegre, RS
}

\begin{abstract}
Resumo: Estudos sobre o tema Gestão de Design vêm sendo desenvolvidos mundialmente, em especial em centros de pesquisa de países como França, Portugal, Estados Unidos e Itália. No Brasil, embora existam instituições de ensino que se destacam em pesquisas sobre Gestão de Design, o cenário ainda é pouco conhecido. Este trabalho objetiva realizar uma revisão sistemática da literatura acadêmica acerca do tema gestão de design, mapeando a produção intelectual desenvolvida nos últimos vinte anos nos programas de pós-graduação brasileiros. A pesquisa foi realizada na world wide web, utilizando como sistema de busca banco de dados de teses e dissertações, sites de busca e sites das bibliotecas universitárias brasileiras, utilizando as palavras chave 'gestão de design', 'gestão do design', 'design estratégico', 'designer' e 'gestor de design'. Os resultados encontrados evidenciam o estado da arte e a evolução da pesquisa sobre o tema em questão, bem como um panorama geral sobre o atual estágio em que os núcleos de pesquisa e os estudos sobre Gestão de Design se encontram no Brasil.
\end{abstract}

Palavras-chave: Gestão de Design. Revisão Sistemática. Estado da Arte. Teses. Dissertações.

Abstract: Studies about the design management theme had being developed worldwide, especially in research centers in countries like France, Portugal, USA and Italy. In Brazil, although educational institutions who excel in research on Design Management, the scenario is still unclear. This work aims at a systematic review of academic literature on the subject of design management, mapping the intellectual production developed in the last twenty years in the post graduate programs, in Brazil, addressing completely or partly the Design Management subject. The research was conducted on the world wide web, using search engine database of theses and dissertations, search engines and websites of Brazilian university libraries, using the keywords 'design management', 'strategic design', 'designer' and 'design manager'. The results show the state of the art and the evolution of research on the subject in question, as well as an overview about the current stage in which the research center and studies on design management take place in Brazil.

Keywords: Design Management. Systematic Revision. State of the Art. Theses. Dissertations.

\section{INTRODUÇÃO}

As primeiras discussões sobre o tema Gestão de Design ou Design Management iniciaram-se na Grã-Bretanha. Farr (1966) observou uma nova função entre os meios de gestão: o gestor de design. Este novo profissional teria a missão 
de proporcionar uma comunicação mais efetiva entre os designers externos e as organizações. Em 1975, Bill Hannon e o Massachusetts College of Art fundaram o DMI (Design Management Institute), em Boston nos Estados Unidos (BORJA DE MOZOTA, 2003), sendo este Instituto uma importante referência na área até os dias de hoje.

Ao longo das últimas décadas, a Gestão de Design vem sendo discutida mundialmente como um fator-chave para o sucesso corporativo. Estudos internacionais de autores como: GORB (1990), BRUCE, COOPER e VAZQUEZ (1999), BORJA DE MOZOTA (2003), BEST (2006), entre outros, se tornaram referências no assunto. Além destes, merecem destaque os trabalhos elaborados por institutos de pesquisa como: o DMI nos Estados Unidos, ICSID (International Council of Societies of Industrial Design) no Canadá, o CPD (Centro Português de Design) em Portugal, o DDC (Centro de Design da Dinamarca) e o EID (Instituto Europeu de Design) na Itália.

Atualmente, o Brasil também conta com pólos de conhecimento e de produção intelectual acerca da Gestão de Design, bem como com periódicos especializados na área de Design, com publicações sobre o tema em questão. Neste contexto, os programas de Pós-Graduação vinculados a Instituições de Ensino vêm desenvolvendo estudos relacionados à Gestão de Design em diversos setores industriais. Neste âmbito, pesquisas como: a atuação e o papel do profissional de design, o design inserido nos objetivos estratégicos de empresas e como a Gestão de Design pode ser mais bem compreendida e utilizada nas organizações, aparecem em estudos que objetivam desenvolver um melhor entendimento do tema visando a eficiência corporativa.

Definições sobre gestão de design surgem na tentativa de encontrar uma explicação especificamente aplicada às organizações. O ICSID (International Council of Societies of Industrial Design) adota o conceito datado de 1977 de Tomas Maldonado salientando que, conforme a definição de gestão do design, o ato de projetar a forma constitui a coordenação, a integração e a articulação de todos os fatores que participam do processo construtivo da forma do produto. Logo, refere-se ao uso, consumo individual ou social do produto, ou seja, fatores funcionais, simbólicos ou culturais, bem como aos que se referem à produção: fatores técnicoeconômicos, técnico-construtivos, técnico-sistemáticos, técnico-produtivos e técnico- 
distributivos. Em 1990, Gorb abordou a relação entre a aplicação dos recursos de design que uma empresa dispõe e os objetivos estratégicos desta. Em contrapartida à especificidade de Maldonado com relação aos fatores que participam da construção do produto, Gorb traz a palavra estratégia ligada à Gestão de Design, sugerindo a definição em sentido mais amplo. Nota-se que a Gestão de Design ultrapassa a esfera de desenvolvimento de produtos e consolida-se na esfera empresarial. Em 1997, o Centro Português de Design lançou o Manual de Gestão de Design, que entende a existência da atuação da Gestão de Design em dois níveis: de projeto e corporativo como um todo. O nível de projeto é mais restrito e específico, e diz respeito à gestão do projeto de design. De outra forma, a atuação em nível corporativo é mais ampla e destaca-se na preparação da cultura organizacional para a criação e desenvolvimento de novos produtos, proporcionando meios e condições para que isso aconteça.

Em 1998, Wolf definiu, com base nos objetivos da corporação, que a Gestão de Design é responsável também pela organização e coordenação de todas as atividades de design. Nota-se, nesta afirmação, um conceito genérico de gestão aplicado ao contexto com a presença da palavra 'design'. Já Kistmann (2001) defendeu o termo Gestão do Design como uma competência central, vinculado diretamente à política estratégica das corporações. Em seu livro intitulado Design Management, Borja de Mozota (2003) definiu Gestão de Design como a implantação do design como um programa formal de atividades na organização, reconhecendo sua relevância para os objetivos de longo prazo da companhia, coordenando os seus recursos em todos os níveis da atividade corporativa, almejando alcançar os objetivos da empresa. Os autores citados entendem a Gestão de Design com uma ação mais ampla e global na companhia, posicionando o design num patamar maior de responsabilidades na corporação.

Corroborando o conceito da Gestão de Design atuando em nível mais amplo e global na companhia, Sopladore e Demarchi (2004) destacaram a necessidade de condicionar recursos e métodos, e assim organizar o ambiente de maneira a propiciar o surgimento de novos produtos. Avendaño (2005) destacou a interação entre os setores da empresa possibilitando uma participação mais ativa do design nas decisões dos produtos. Ainda com relação à definição de Gestão de Design, Rodrigues (2005) definiu a gestão de design como uma ferramenta estratégica que 
estabelece a inserção adequada do design na empresa. Para este autor, esta ferramenta gerencia os recursos humanos e materiais da organização, integrando áreas (especialistas em várias atividades) à alta administração, desde a concepção de um projeto até seu lançamento no mercado, sendo ainda eficiente para criar e implantar uma cultura empresarial que afete a imagem da empresa positivamente. Visualizando a Gestão de Design como uma "ponte entre o design e o negócio", McBride (2007) defendeu a liderança focada no design, que vai além da estratégia, transformando experiências, companhias e oportunidades.

O DMI (2010) entende que existem duas maneiras de compreender a gestão de design. Em nível geral, entende a gestão de design como a face de negócio do design, pois engloba os processos em curso, as decisões de negócios bem como as estratégias que permitem a inovação e a criação de design efetivo em produtos, serviços, comunicações, ambientes e marcas, melhorando a qualidade de vida e proporcionando sucesso organizacional. Já em nível mais específico, salienta que a gestão do design visa unir design, inovação, tecnologia, gestão e clientes para oferecer vantagens competitivas através de três linhas base (econômica, social/cultural e fatores ambientais), promovendo a colaboração e a sinergia entre design e negócios e assim, melhorando a eficácia do design (DMI, 2010). Outro instituto de pesquisa atuante na área, o Design Council (2010) define a Gestão de Design como sendo uma atividade total de design, desde a implementação e organização de todo o processo de desenvolvimento de novos produtos e serviços até a administração e o alcance de um melhor desempenho da empresa.

Quando os estudos sobre Gestão de Design iniciaram no Brasil, as pesquisas, em sua maior parte, eram desenvolvidas em programas de pósgraduação ligados a outros cursos, como a Administração e a Engenharia de Produção. A UFRJ (Universidade Federal do Rio de Janeiro), através do programa de pós-graduação da engenharia de produção, foi pioneira em 1995 nos estudos acerca do tema Gestão de Design. Também no Estado do Rio de Janeiro, a PUC-RJ (Pontifícia Universidade Católica do Rio de Janeiro), em 1994, dentro do Departamento de Artes \& Design, começou a oferecer o mestrado em Design e, no ano de 2003, lançou o primeiro curso de doutorado em design no Brasil. Em 1999, a UFSC (Universidade Federal de Santa Catarina) criou o curso de graduação em design e em 2006 lançou o primeiro programa de pós-graduação stricto sensu em 
design gráfico no país, que atualmente conta com o Núcleo de Gestão de Design. A UFPR (Universidade Federal do Paraná) lançou em 2005 o primeiro programa de pós-graduação stricto sensu em design do sul do Brasil. Instituições de Ensino como a Unisinos, a UFRGS (Universidade Federal do Rio Grande do Sul) e a UEMG (Universidade Estadual de Minas Gerais) desenvolveram recentemente núcleos de estudos com linhas de pesquisas para tratar de temas ligados ao gerenciamento de design.

Observa-se um crescente desenvolvimento de programas de pós-graduação em Design e áreas afins no Brasil desde o início dos anos 1990. Entretanto, constantemente surgem discussões sobre a carência de material no que concerne a Gestão de Design no Brasil. Devido a estas constantes discussões, uma revisão sistemática de literatura é proposta com o intuito de mapear o estado da arte de teses e dissertações brasileiras, desenvolvidas nos últimos vinte anos, que abordem o tema Gestão de Design, bem como o desenvolvimento de pólos de conhecimento sobre o tema em questão, evidenciando oportunidades de pesquisa na área.

\section{PROCEDIMENTOS METODOLÓGICOS}

Para o presente estudo foi desenvolvida uma revisão sistemática, de natureza aplicada e com objetivos de caráter exploratório. Foi realizado um levantamento qualitativo das teses e dissertações de programas de pós-graduação brasileiros que tratam do tema Gestão de Design. De acordo com Sampaio e Mancini (2007), revisão sistemática é um meio de pesquisa que se baseia em fontes de dados da literatura sobre um tema específico, viabilizando um resumo de todos os estudos sobre uma determinada intervenção. As revisões sistemáticas possibilitam a incorporação de uma gama maior de resultados relevantes, ao invés de restringir as conclusões das pesquisas de determinado estudo à leitura de poucos materiais. Todavia, dependem da qualidade das fontes primárias pesquisadas. Para o desenvolvimento coerente de um processo de pesquisa, em uma revisão sistemática, uma acertada seqüência de passos metodológicos deve ser observada. Neste estudo, adotou-se a metodologia de Sampaio e Mancini (2007), conforme o quadro 1. 
Quadro 1 - Etapas da Revisão Sistemática

\begin{tabular}{|c|c|}
\hline $\begin{array}{l}\text { Etapas para a Revisão } \\
\text { Sistemática de Literatura }\end{array}$ & Etapas da Pesquisa de Teses e Dissertações no Brasil \\
\hline $\begin{array}{l}\text { 1) Definir a pergunta } \\
\text { científica }\end{array}$ & $\begin{array}{l}\text { Qual o atual estágio de produção intelectual desenvolvida nos } \\
\text { programas de pós-graduação brasileiros sobre o tema Gestão de } \\
\text { Design? }\end{array}$ \\
\hline $\begin{array}{l}\text { 2) Identificar as bases de } \\
\text { dados a ser consultadas, } \\
\text { definir palavras-chave e } \\
\text { estratégias de busca }\end{array}$ & $\begin{array}{l}\text { A pesquisa foi realizada na world wide web utilizando como sistema } \\
\text { de busca banco de dados de teses e dissertações, partindo das } \\
\text { palavras-chave: 'Gestão de Design', 'Gestão do Design', 'Design } \\
\text { Estratégico', 'designer' e 'gestor de design'. Os trabalhos foram } \\
\text { coletados na world wide web e através de solicitações aos autores e } \\
\text { ao programa COMUT das Bibliotecas das Universidades Federais. }\end{array}$ \\
\hline $\begin{array}{l}\text { 3) Estabelecer critérios para } \\
\text { a seleção dos artigos a } \\
\text { partir da busca }\end{array}$ & $\begin{array}{l}\text { A partir da busca, os trabalhos foram lidos e separados em três } \\
\text { grupos: os que versam do tema Gestão de Design, os que tratam } \\
\text { parcialmente do tema e os que não tratam do tema em questão. Este } \\
\text { último grupo foi excluído da pesquisa. }\end{array}$ \\
\hline $\begin{array}{l}\text { 4) Conduzir busca nas } \\
\text { bases de dados escolhidas } \\
\text { e com base na(s) } \\
\text { estratégia(s) definida(s) }\end{array}$ & $\begin{array}{l}\text { Durante o mês de agosto de } 2010 \text { foram feitas buscas sobre as teses } \\
\text { e dissertações apresentadas nos Centros de Pesquisa brasileiros. }\end{array}$ \\
\hline $\begin{array}{l}\text { 5) Comparar as buscas dos } \\
\text { examinadores e definir a } \\
\text { seleção inicial de artigos }\end{array}$ & $\begin{array}{l}\text { Analisados os artigos da busca, foram selecionados } 63 \text { trabalhos } \\
\text { para esta pesquisa. }\end{array}$ \\
\hline $\begin{array}{l}\text { 6) Aplicar os critérios na } \\
\text { seleção dos artigos e } \\
\text { justificar possíveis } \\
\text { exclusões }\end{array}$ & $\begin{array}{l}\text { Os trabalhos, para serem selecionados, deveriam obrigatoriamente } \\
\text { abordar, em algum momento, o tema Gestão de Design. Trabalhos } \\
\text { que não abordassem de nenhuma maneira esse tema foram } \\
\text { excluídos. }\end{array}$ \\
\hline $\begin{array}{l}\text { 7) Analisar criticamente e } \\
\text { avaliar todos os estudos } \\
\text { incluídos na revisão }\end{array}$ & $\begin{array}{l}\text { As informações dos trabalhos foram organizadas e tabeladas, de } \\
\text { maneira que fosse possível desenvolver comparações e análises. }\end{array}$ \\
\hline $\begin{array}{l}\text { 8) Preparar um resumo } \\
\text { crítico, sintetizando as } \\
\text { informações disponibilizadas } \\
\text { pelos artigos que foram } \\
\text { incluídos na revisão }\end{array}$ & $\begin{array}{l}\text { Um resumo crítico em formato de tabela foi realizado, onde as } \\
\text { informações de cada trabalho julgadas relevantes para este estudo } \\
\text { foram elencadas, como: tipo, ano de publicação, centros de } \\
\text { pesquisa, formação dos autores, programas de pós-graduação, } \\
\text { palavras-chave, métodos de pesquisa utilizados, setores de } \\
\text { atividade, papel do profissional de design e objetivos dos trabalhos. }\end{array}$ \\
\hline $\begin{array}{l}\text { 9) Apresentar uma } \\
\text { conclusão, informando a } \\
\text { evidência sobre os efeitos } \\
\text { da intervenção }\end{array}$ & $\begin{array}{l}\text { A partir da análise das informações contidas nas } 56 \text { dissertações e } \\
\text { nas sete teses foi possível mapear o atual estágio da produção } \\
\text { intelectual desenvolvida nos programas de pós-graduação brasileiros } \\
\text { sobre o tema Gestão de Design }\end{array}$ \\
\hline
\end{tabular}

Fonte: Adaptado de Sampaio; Mancini (2007)

A pesquisa foi realizada inicialmente na world wide web utilizando como sistema de busca bancos de dados de teses e dissertações (portal da Capes, portal Domínio Público e biblioteca digital brasileira de teses e dissertações do Instituto Brasileiro de Informação em Ciência e Tecnologia), partindo de termos como 
'Gestão de Design', 'Gestão do Design', 'Design Estratégico', 'designer' e 'gestor de design'. Foram identificados 278 trabalhos, entre teses e dissertações. Uma triagem foi feita, com o intuito de eliminar os trabalhos que não estivessem dentro do tema de pesquisa. Para verificar se esses trabalhos tratavam do tema Gestão de Design, completamente ou em parte, uma seleção foi realizada utilizando como critérios a leitura do resumo e palavras-chave e, quando disponível na internet, da introdução dos trabalhos. Depois de serem selecionados, foram analisadas as bibliografias destes trabalhos, com o propósito de identificar a eventual existência de outras dissertações e teses que não tenham sido encontradas na primeira seleção. Foram encontradas desta forma mais três dissertações e uma tese.

Foram selecionadas então sete teses e 56 dissertações, totalizando 63 trabalhos. Inicialmente, utilizou-se a world wide web como meio de obter os trabalhos na íntegra em formato digital. Quando o arquivo com o estudo não era encontrado, enviava-se um email para os autores das teses e dissertações solicitando, se possível, o envio do trabalho. Obteve-se $63 \%$ de retorno com os arquivos em meio digital. Para conseguir os outros $37 \%$ restantes foi utilizado o sistema COMUT (Programa de Comutação Bibliográfica), disponibilizado pela Universidade Federal do Rio Grande do Sul - UFRGS, onde o material impresso foi enviado pelo correio. Os dados foram tabulados conforme ilustrado na Figura 1.

Figura 1 - Extrato da Tabulação das Informações.

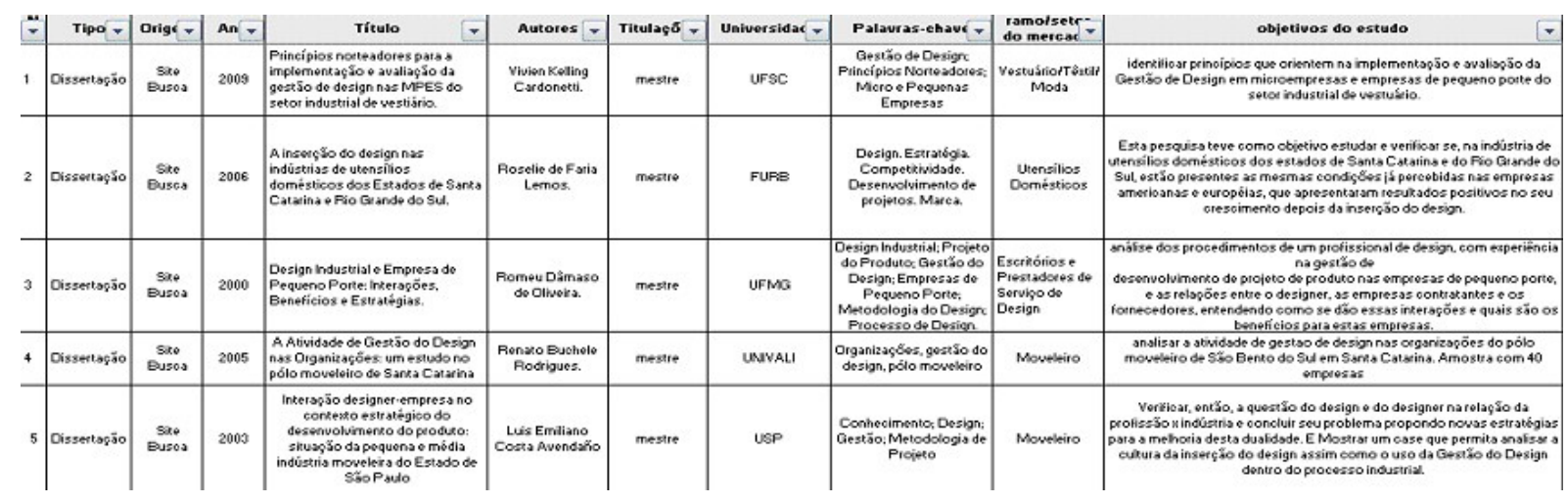

Os resultados foram obtidos pela leitura integral das teses e dissertações com a tabulação das informações julgadas relevantes para esta pesquisa, respeitando os seguintes agrupamentos: tipo (tese ou dissertação), ano de publicação, Instituição de Ensino onde foi desenvolvida a pesquisa, Programa de Pós-Graduação no qual o 
trabalho estava vinculado, formação dos autores das teses e dissertações, palavraschave, procedimento de pesquisa utilizado, setor de atividade na qual a pesquisa foi desenvolvida, papel do profissional de design, objetivos do estudo e uma análise geral sobre os assuntos tratados no artigo. A Figura 2 explicita sucintamente as etapas da pesquisa.

Figura 2 - Etapas da Pesquisa.

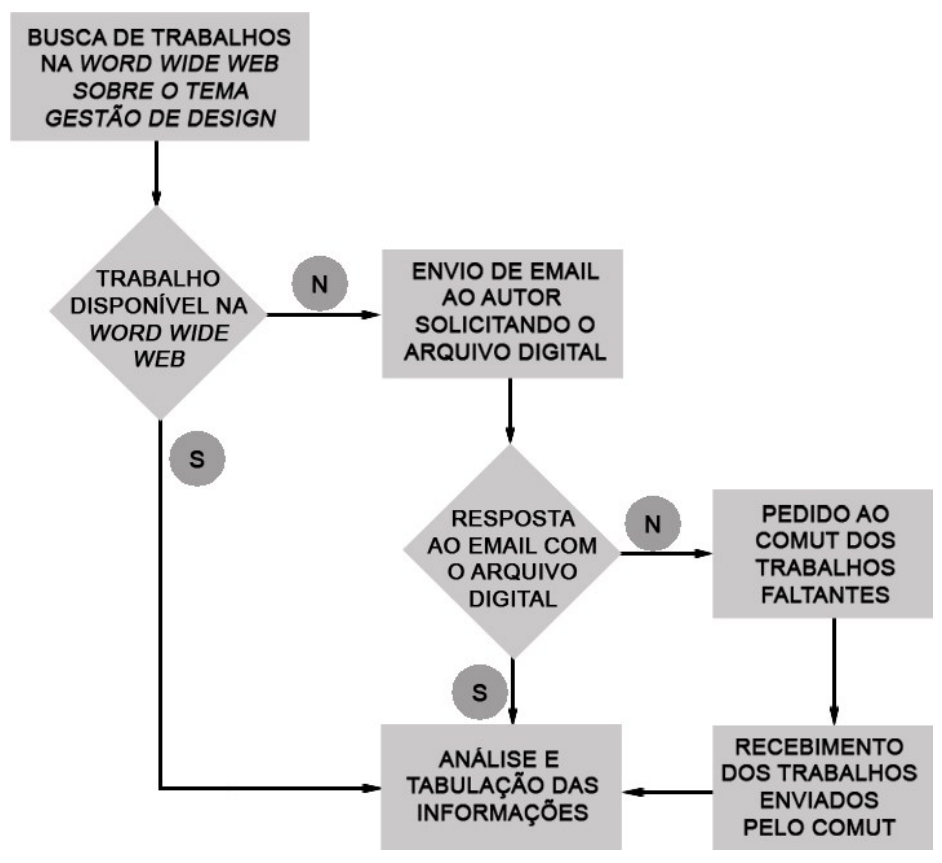

Fonte: Elaborado pelos autores

\section{RESULTADOS}

Para apresentação dos resultados, utilizou-se a subdivisão nos seguintes tópicos de análise: tipologia, ano de publicação, instituições de ensino, programas de pós-graduação, formação dos autores, palavras-chave, procedimentos de pesquisa utilizados, setores de atividade, reconhecimento do papel do profissional de design e objetivos dos trabalhos.

\subsection{Tipologia}

Do universo de 63 trabalhos que tratam, em parte ou totalmente, do tema Gestão de Design, foram encontradas 56 dissertações e sete teses. Seis teses foram desenvolvidas em programas de pós-graduação em Engenharia de Produção 
e um no programa de Desenvolvimento Sustentável. Não foram encontradas teses sobre o tema em questão desenvolvidas em programas de pós-graduação em design, tendo em vista a carência de programas de doutorado na área do design. Das sete teses, quatro foram desenvolvidas na UFSC, duas na UFRJ e uma no UFPA.

\subsection{Ano de Publicação}

Com relação ao ano de publicação, nota-se um crescente com o passar dos anos na produção das dissertações. Foram pesquisados os últimos vinte anos, entretanto o primeiro trabalho publicado data de 1994. Como no ano de 2010 foram considerados somente os primeiros oito meses, pode-se estimar que mais algum trabalho seja publicado até o final do ano. Através do gráfico da figura 3 , pode-se visualizar o crescimento das pesquisas acadêmicas na área de Gestão de Design. Pesquisa similar foi feita por Wolff et al. (2010) em dois repositórios de artigos de design do Brasil (o Congresso Brasileiro de Pesquisa e Desenvolvimento em Design - P\&D e a Revista Estudos em Design). Os autores destacam que nos anos 2000 ocorreram grandes debates e publicações no exterior, "tanto em livros quanto no surgimento de seminários, congressos, journals e até mesmo de programas de pósgraduação na área" (WOLFF et al., 2010).

Figura 3 - Quantidade versus ano de publicação de teses e dissertações no Brasil que tratam do tema Gestão de Design

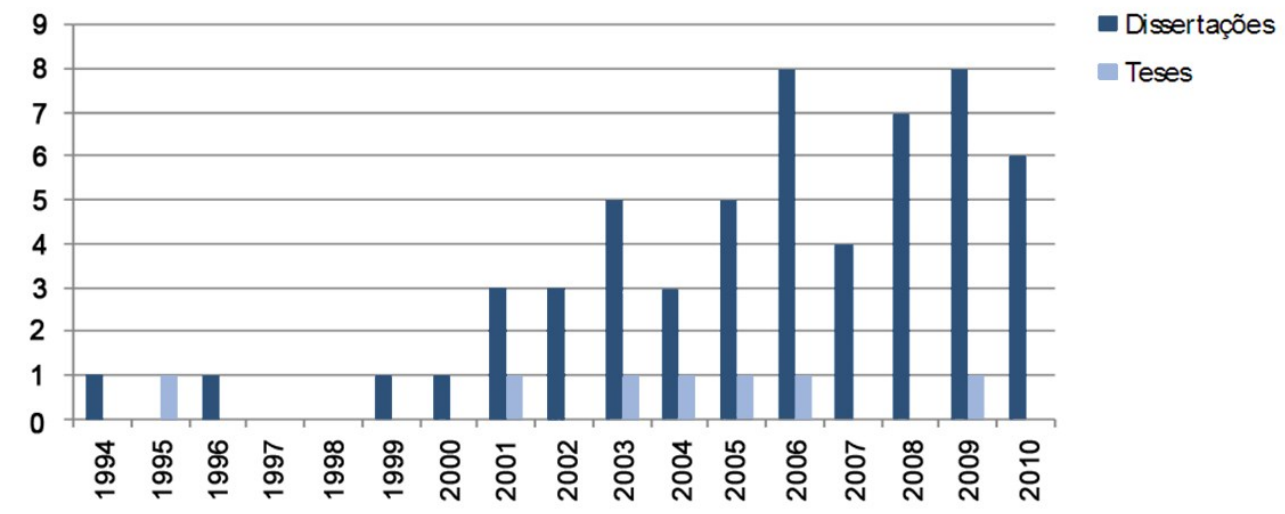

Fonte: Coleta de dados 


\subsection{Instituições de Ensino}

No Brasil, destacam-se estudos sobre o tema Gestão de Design, desenvolvidos por centros de pesquisa em Estados como: São Paulo, Rio de Janeiro, Santa Catarina, Minas Gerais, Paraná, Rio Grande do Sul, Pará, Rio Grande do Norte, Paraíba e Pernambuco, além do Distrito Federal (Figura 4).

Figura 4: Estados do Brasil versus quantidade de teses e dissertações que tratam do tema Gestão de Design

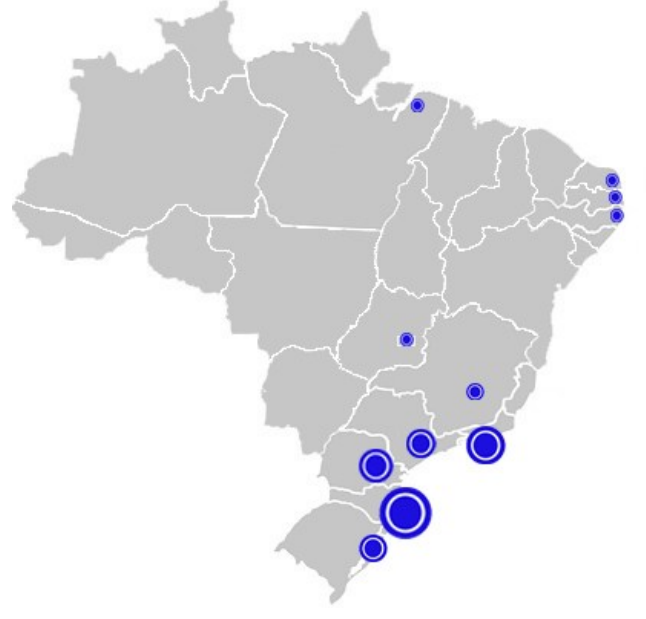

Fonte: coleta de dados

No gráfico da figura 5 estão representadas as Instituições de Ensino que mais publicaram teses e dissertações nos últimos vinte anos, bem como as quantidades dos trabalhos.

Figura 5 - Instituições de Ensino no Brasil e número de teses e dissertações que tratam do tema Gestão de Design

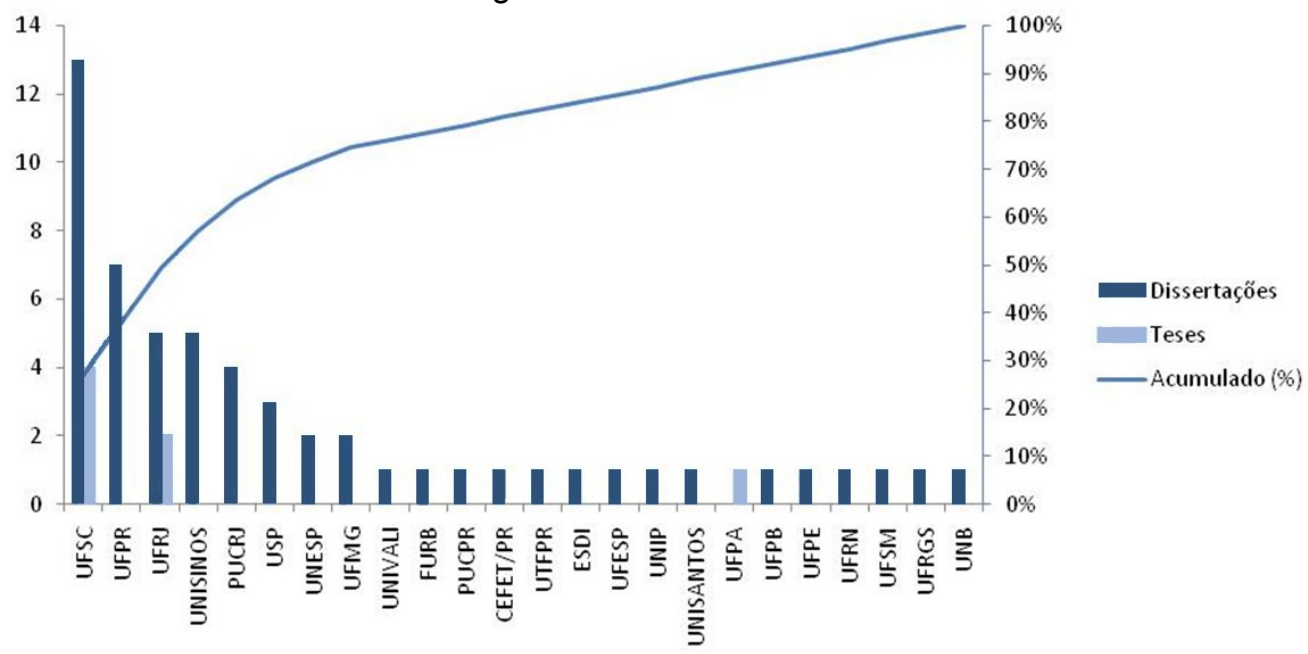

Fonte: coleta de dados

Revista Produção Online. Florianópolis, SC, v.11, n. 2, p. 565-594, abr./jun., 2011. 
De acordo com o gráfico de Pareto da figura 5 , os centros de pesquisa UFSC, UFPR, UFRJ, UNISINOS, PUCRJ, USP, UNESP e UFMG são responsáveis por $80 \%$ da produção das teses e dissertações. A UFSC destaca-se com 17 trabalhos publicados na área de Gestão de Design. É importante ressaltar que, das 13 dissertações desenvolvidas, nove foram desenvolvidas no programa de pósgraduação em Engenharia de Produção e, a partir de 2009, houve uma migração das produções para o Núcleo de Design e Expressão Gráfica da Universidade, sendo esse responsável pelas última quatro dissertações realizadas. Já as quatro teses foram desenvolvidas entre 2001 e 2006 no programa de pós-graduação em Engenharia de Produção.

Com sete trabalhos cada, encontram-se a UFPR e a UFRJ. Na UFPR foram encontradas somente dissertações, sendo que três dessas foram desenvolvidas no programa de pós-graduação da Engenharia Mecânica entre 2005 e 2006. A partir de 2008 as dissertações ligadas ao tema gestão de design passaram a ser realizadas no departamento de design, sendo este então responsável pelas últimas quatro dissertações. A UFRJ foi pioneira na realização de teses e dissertações na área da gestão de design - a primeira dissertação foi desenvolvida em 1994 e a primeira tese em 1995. O Programa de Pós-Graduação e Pesquisa de Engenharia, também denominado COPPE, foi o responsável pelas duas teses e cinco dissertações. Esses sete trabalhos ocorreram no período de 1994 a 2004. Acredita-se que, com a abertura de outros programas de pós-graduação em design, a Engenharia deixou de produzir trabalhos relacionados à área em questão.

A Unisinos, situada no Rio Grande do Sul foi responsável pelo desenvolvimento de cinco dissertações. A primeira dissertação realizada sobre o tema em questão aconteceu em 2006, vinculada ao departamento de Administração de Empresas. Posteriormente, em 2009, o departamento da Engenharia de Produção realizou outra dissertação. Estas duas dissertações tratam do tema gestão de design. Com o surgimento da Escola de Design da Unisinos, três dissertações foram defendidas em 2010 relacionadas ao Design Estratégico, tema que a Escola adota como enfoque de pesquisa atualmente. Já na PUC-RJ, das quatro dissertações que foram desenvolvidas e defendidas entre 2007 e 2008, uma foi realizada no departamento de Administração de Empresas e defendida em 2007 e as outras três foram realizadas no departamento de Design \& Artes. 


\subsection{Programas de pós-graduação}

Com relação ao universo das 63 teses e dissertações que tratam do tema gestão de design, a Engenharia de Produção é o programa de pós-graduação que mais publicou teses e dissertações no Brasil, com um total de 23 dissertações e uma tese. Logo após encontra-se o programa de pós-graduação em design, que apresenta 19 dissertações. O programa de Administração de Empresas vem em terceiro lugar com seis dissertações. A UFPR, em especial, é responsável pela publicação de três dissertações da Engenharia Mecânica. Já o Desenvolvimento Sustentável conta com uma tese e uma dissertação publicadas na área em questão. O CEFET/PR desenvolveu uma dissertação na área da tecnologia e a UNISANTOS uma dissertação na área da gestão de negócios. A USP é responsável por três dissertações, uma em cada área da Arquitetura, Administração de Empresas e Comunicação. O gráfico da figura 6 demonstra os programas de pós-graduação que desenvolveram as teses e dissertações versus a quantidade dos trabalhos desenvolvidos.

Figura 6 - Programas de pós-graduação no Brasil versus quantidade de teses e dissertações que tratam do tema Gestão de Design

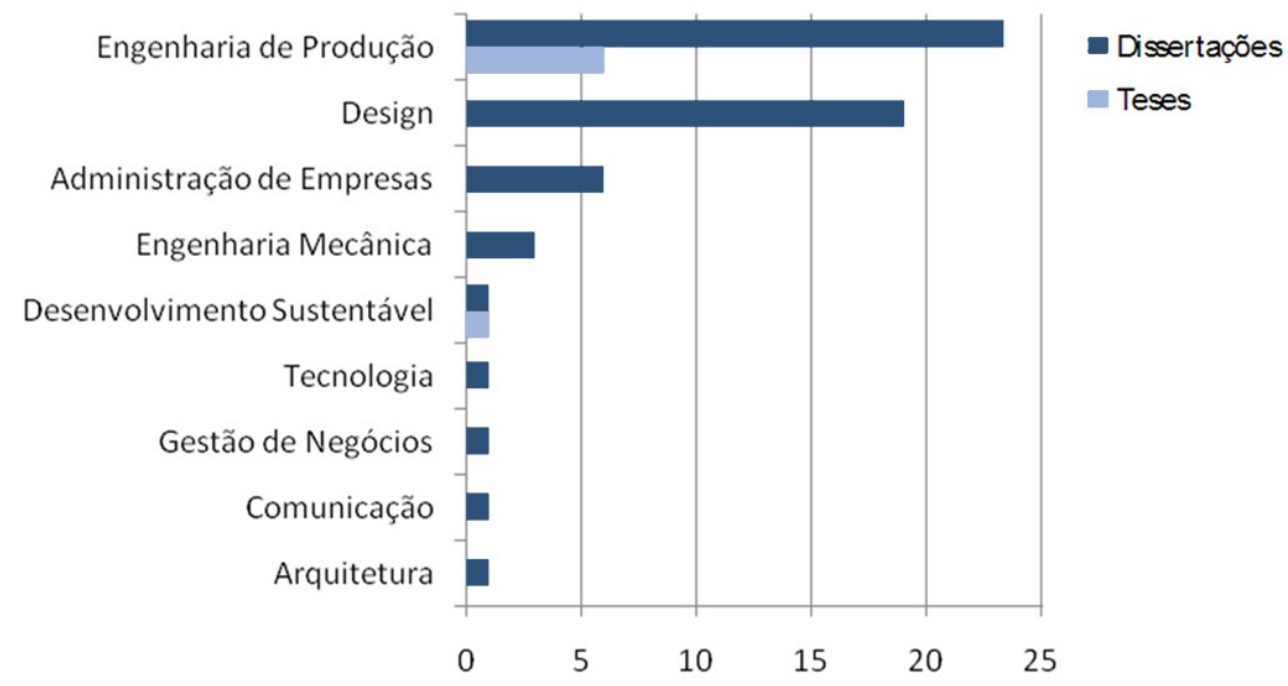

Fonte: coleta de dados

\subsection{Formação dos autores}

A tabela 1 evidencia com destaque que a grande maioria dos autores (32 ou $54 \%$ do total) tem formação superior com graduação em Desenho Industrial. Adiante 
está o curso de graduação em Administração de Empresas, seguido de Educação Artística, Arquitetura, Ciências Contábeis, com cinco, quatro, três e dois autores, respectivamente. Com um autor cada estão as graduações de Desenho e Plástica, Turismo, Comunicação Visual, Engenharia Civil, Filosofia, Física, Letras, Moda e Estilismo, Secretariado Executivo, Serviço Social, Tecnologia do Vestuário, Tecnologia em Mecânica e Tecnologia em Moda e Estilo. Importante salientar que para os 63 trabalhos existem 61 autores, já que dois autores têm tabuladas suas teses e dissertações nesta pesquisa. Não foram encontradas informações sobre a formação superior de outros dois autores desta pesquisa, portanto a análise deste item totaliza 59 autores.

Tabela 1 - Formação superior dos autores das teses e dissertações que tratam do tema Gestão de Design

\begin{tabular}{lcc}
\hline Graduação & Quantidade & $\%$ \\
\hline Desenho Industrial & 32 & $54 \%$ \\
Administração de Empresas & 5 & $8 \%$ \\
Educação Artística & 4 & $7 \%$ \\
Arquitetura & 3 & $5 \%$ \\
Ciências Contábeis & 2 & $3 \%$ \\
Desenho e Plástica & 1 & $2 \%$ \\
Turismo & 1 & $2 \%$ \\
Comunicação Visual & 1 & $2 \%$ \\
Engenharia Civil & 1 & $2 \%$ \\
Filosofia & 1 & $2 \%$ \\
Física & 1 & $2 \%$ \\
Letras & 1 & $2 \%$ \\
Moda e Estilismo & 1 & $2 \%$ \\
Secretariado Executivo & 1 & $2 \%$ \\
Serviço Social & 1 & $2 \%$ \\
Tecnologia do Vestuário & 1 & $2 \%$ \\
Tecnologia em Mecânica & 1 & $2 \%$ \\
Tecnologia em Moda e Estilo & 1 & $2 \%$ \\
\hline
\end{tabular}

Fonte: coleta de dados 


\subsection{Palavras-chave}

\subsubsection{Com maior frequência nas teses e dissertações}

'Design' foi a palavra-chave de maior freqüência, com ocorrência em 26 trabalhos (Figura 7). Em segundo lugar está a expressão 'Gestão de Design', aparecendo 16 vezes. Posteriormente, com 13 ocorrências, está a expressão 'Gestão do Design'. Essas duas expressões aparecem separadas, pois existe uma discussão acerca do significado de cada uma. Entretanto, nestre trabalho, será adotada a definição de Martins (2004), que constata que a expressão 'De design' é mais genérica e engloba todos os segmentos, como, por exemplo, gestão de negócios. Martins (2004) ainda salienta que 'Do Design', significa algo restrito, ou seja, gestão de um único segmento. A seguir aparecem palavras como: 'competitividade', 'estratégia', 'inovação', 'gestão' e 'organizações' que estão diretamente ligadas às áreas da Administração de Empresas e da Engenharia de Produção. A palavra 'moda' destaca o segundo maior segmento de mercado de interesse na realização de pesquisas na área, conforme será evidenciado no item 3.7 a seguir. Além destas, a expressão 'Design Estratégico' também consta na lista das palavras-chave mais referenciadas. Esta também está ligada a Gestão de Design, entretanto é considerada como tendo caráter mais restrito e está relacionada à estratégia empresarial.

Figura 7 - Palavras-chave mais encontradas nas teses e dissertações.

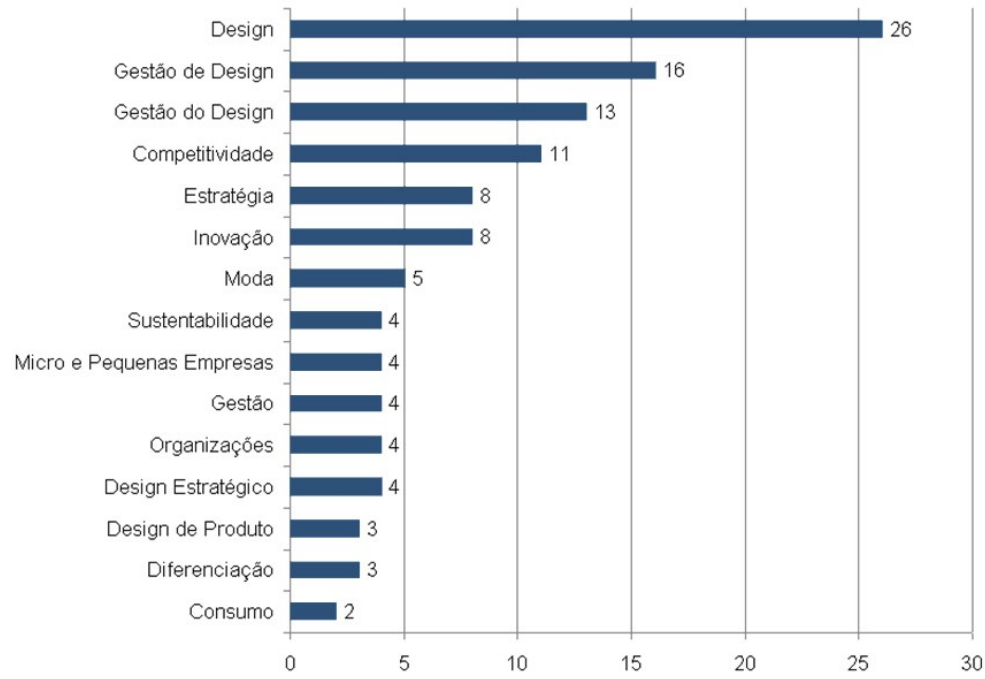

Fonte: coleta de dados 


\subsubsection{Agrupamentos por similaridade com maior freqüência nas teses e dissertações}

$\mathrm{Na}$ tabela 2, observam-se 37 citações de expressões como 'Gestão de/do/em Design', 'Gestão Estratégica de/do Design', 'Design Estratégico' e 'Gestão em Design de Moda'. Nota-se certa insegurança na utilização de uma nomenclatura que defina claramente a Gestão de Design. Pode-se visualizar ainda agrupamentos de uma variedade de expressões que giram em torno de palavras ligadas às áreas da Administração de Empresas e da Engenharia de Produção, como: 'competitividade', 'estratégia', 'inovação', 'gestão' e 'organizações'. Os setores de maior interesse em pesquisas relacionadas à gestão de design também aparecem representados por palavras relacionadas à 'moda' e ao 'pólo moveleiro'.

Tabela 2 - Palavras-chave agrupadas por similaridade em teses e dissertações

\begin{tabular}{cc}
\hline Agrupamento das Palavras-chave por Similaridade & Quantidade \\
\hline $\begin{array}{c}\text { Gestão de Design/Gestão do Design/Gestão em Design/Gestão em Design de } \\
\text { Moda/Gestão Estratégica do Design/Gestão Estratégica de Design/Design } \\
\text { Estratégico }\end{array}$ & 37 \\
Design/Design Industrial/Projeto & 31 \\
Delo Design & 14 \\
pompetitividade/Diferencial Competitivo/Ferramenta competitiva/Competitividade & 11 \\
Estratégia/Estratégia de Diferenciação/Estratégica Competitiva/Gestão estratégica & 9 \\
Inovação/Inovação pelo Design & 7 \\
Moda/Sistema da Moda/Panorama da Moda Carioca & 6 \\
Micro e Pequenas Empresas/Micro Empresas/Empresas de Pequeno Porte & 6 \\
Gestão/Autogestão/Gerência & 5 \\
Organizações/Empresas & 5 \\
Móveis/Pólo Moveleiro/Setor do Mobiliário & 5 \\
Sustentabilidade/Desenvolvimento Sustentável & 3 \\
Metodologia de Projeto/Metodologia do Design & 3 \\
Diferenciação & 3 \\
Design de Produto & 2 \\
Processo de Design/Processos de Design & 84 \\
Demais palavras-chave &
\end{tabular}

Fonte: coleta de dados 


\subsection{Procedimentos de pesquisa utilizados}

Conforme gráfico da figura 8 , o procedimento de pesquisa mais utilizado nas teses e dissertações foi o estudo de caso, respondendo por $63 \%$ dos trabalhos. 0 levantamento foi o segundo tipo de procedimento mais utilizado, em $21 \%$ dos trabalhos. $6 \%$ dos estudos fizeram uso da pesquisa participante, enquanto que $3 \%$ fizeram uso do procedimento documental e $3 \%$ da bibliográfica. Os procedimentos ex-post facto e experimental foram utilizados em um trabalho cada, representando $2 \%$ para cada trabalho.

Figura 8 - Procedimentos de pesquisa utilizados nas teses e dissertações

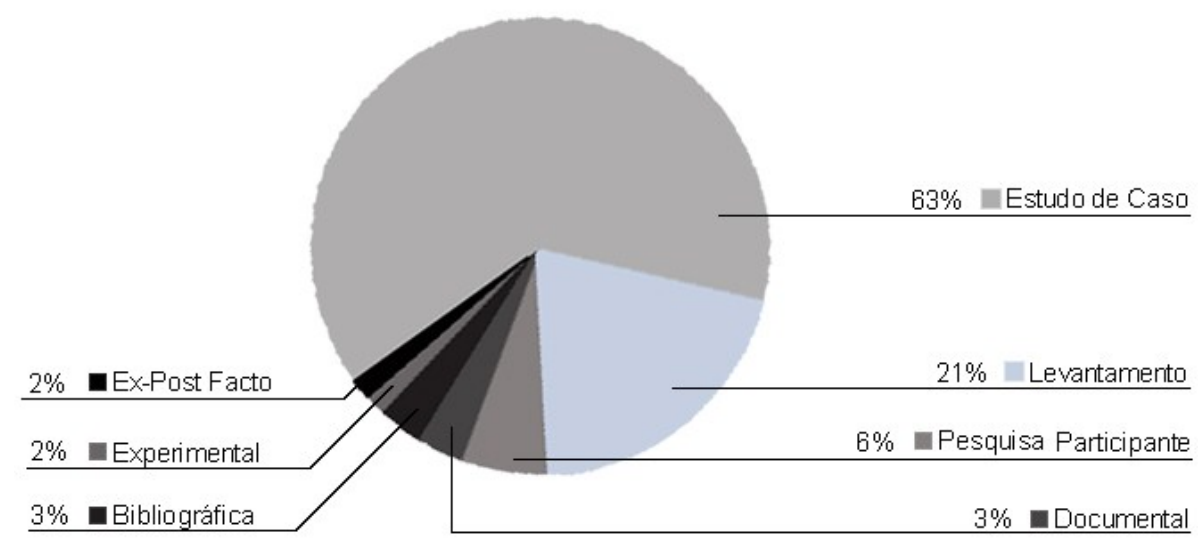

. Fonte: coleta de dados

\subsection{Setores de atividade}

Os setores de atividade referem-se aos setores de mercado escolhidos pelos autores para desenvolver suas pesquisas. Através do Gráfico da Tabela 3, observase que o setor moveleiro, responsável por 16 estudos ( $25 \%$ do total), ainda é o mais procurado para pesquisas na área da gestão de design. Em seguida aparece o setor vestuário, têxtil e da moda, com nove trabalhos desenvolvidos na área. 
Tabela 3 - Setores de atividades estudados versus quantidade de teses e dissertações no Brasil que tratam do tema Gestão de Design

\begin{tabular}{lcc}
\hline Setor de Atividade & Quantidade & $\%$ \\
\hline Moveleiro & 16 & $25 \%$ \\
Vestuário/Têxtil/Moda & 9 & $14 \%$ \\
Embalagens & 3 & $5 \%$ \\
Calçadista & 3 & $5 \%$ \\
Setores Industrial e de Serviço & 2 & $3 \%$ \\
Empresas de Base Tecnológica & 2 & $3 \%$ \\
Alimentício & 2 & $3 \%$ \\
Artesanato & 2 & $3 \%$ \\
Educação & 2 & $3 \%$ \\
Eletrodomésticos & 2 & $3 \%$ \\
Eletro-Eletrônico & 2 & $3 \%$ \\
Escritórios e Prestadores de Serviço de Design & 2 & $3 \%$ \\
Indústria da Porcelana de Mesa & 2 & $3 \%$ \\
Joalheiro & 2 & $3 \%$ \\
Eletrodoméstico, Cerâmico e Instit. Fomento à Indústria & 1 & $2 \%$ \\
Empresas que projetam produtos & 1 & $2 \%$ \\
Empresas vencedoras de um prêmio de design & 1 & $2 \%$ \\
Indústria do Vidro & 1 & $2 \%$ \\
Industrial & 1 & $2 \%$ \\
Industrial Cerâmico & 1 & $2 \%$ \\
Médico-Odonto-Hospitalar e Laboratorial & 1 & $2 \%$ \\
Perfumaria e Cosméticos & 1 & $2 \%$ \\
Projetos Sociais & 1 & $2 \%$ \\
Reciclagem & 1 & $2 \%$ \\
Utensílios Domésticos & 1 & $2 \%$ \\
Automotivo & 1 & $2 \%$ \\
\hline Fonte: coleta de dados & 1 & $2 \%$ \\
\hline & & $2 \%$ \\
\hline
\end{tabular}

Fonte: coleta de dados

\subsection{Reconhecimento do Papel do Profissional de Design}

Nos trabalhos pesquisados, o reconhecimento do papel do profissional de design chamou bastante atenção, pela falta de estudo com maior ênfase da figura deste indivíduo. $25 \%$ das teses e dissertações consideraram o papel do profissional de design e destacaram uma parte de seu estudo neste assunto. $38 \%$ dos trabalhos trataram brevemente do assunto, destacando pouco reconhecimento para o papel 
deste profissional. $37 \%$ dos estudos não fizeram referência ao papel do profissional de design em suas pesquisas. Os dados são apresentados no gráfico da figura 9.

Figura 9 - Reconhecimento do papel do profissional de design

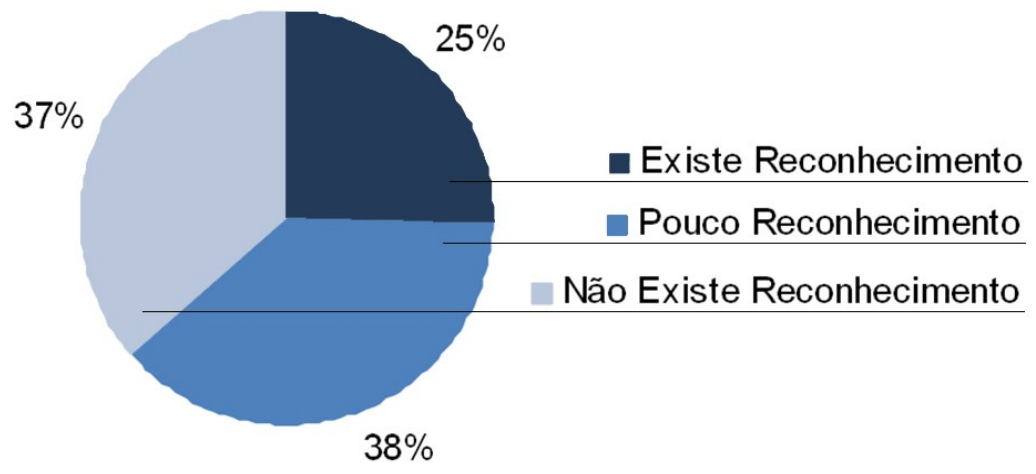

Fonte: coleta de dados

\subsection{Objetivos dos trabalhos}

Diversos são os objetivos propostos nas teses e dissertações. Entretanto, para que seja possível uma mensuração, esses objetivos foram agrupados em 5 grandes grupos (figura 10). Observa-se que $32 \%$ dos trabalhos objetivaram estudar/analisar a gestão de design e, na maioria das vezes, sua aplicação em empresas selecionadas para estudo. O estudo do design como um diferencial estratégico, visando ampliar a competitividade das empresas apareceu em $21 \%$ dos objetivos dos trabalhos. Entre os estudos, 14\% destacaram como objetivo a capacitação dos profissionais, designers e colaboradores. Também com 14\% apareceram os trabalhos que tinham como objetivo propor princípios, diretrizes, modelos, metodologias, propostas ou programas de implantação da gestão de design nas empresas.

Figura 10 - Identificação dos objetivos expostos nas teses e dissertações

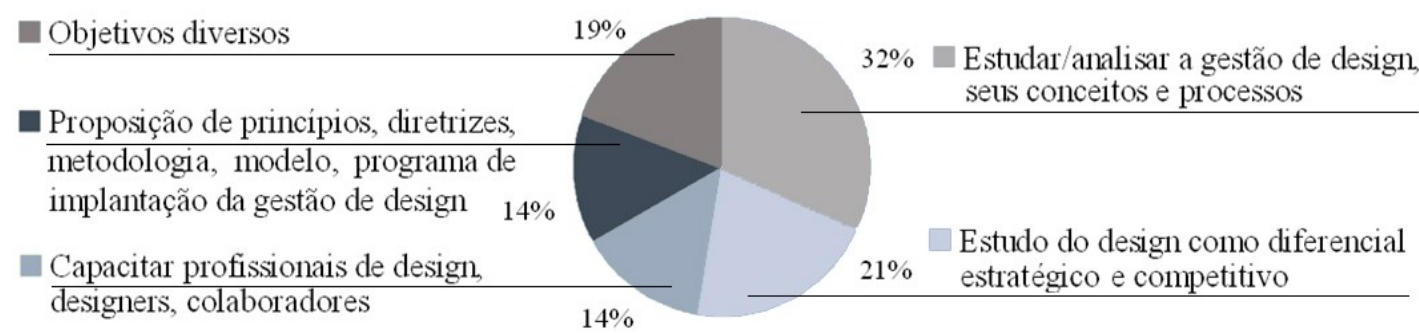

Fonte: coleta de dados

Revista Produção Online. Florianópolis, SC, v.11, n. 2, p. 565-594, abr./jun., 2011. 


\section{DISCUSSÃO}

Estudos acadêmicos, como teses e dissertações, têm se apresentado com constante produção no Brasil. Entretanto, seu difícil acesso nas diversas regiões do país, seja por meio físico ou virtual, ou mesmo a falta de um estudo mais dedicado, ordenado e criterioso sobre o tema proposto torna complexa a troca de conhecimento e evolução de temas como a Gestão de Design.

Com o passar dos anos, as publicações de teses e dissertações se mostraram cada vez mais frequentes e, consequentemente, se percebe um maior interesse pela pesquisa do tema em questão. Ao longo dos últimos vinte anos, observou-se a crescente criação de centros de pesquisa na área do Design e alguns desses, como UEMG, PUCRJ, UFPR, UFSC, UFRGS e Unisinos, desenvolvendo linhas de pesquisa na área da Gestão de Design ou em temas correlatos. Contudo, por serem recentes, poucas Universidades oferecem em seus programas de pósgraduação a modalidade doutorado em Design. Acredita-se que, por este fato, as teses publicadas até o presente momento tenham sido desenvolvidas em outros programas de pós-graduação (PPGs), como na Engenharia de Produção e no Desenvolvimento Sustentável. Apesar da criação recente dos programas de pósgraduação em design, outros PPGs também se mostram abertos e interessados no estudo da gestão de design, como foi evidenciado anteriormente. Entende-se ser positivo esse intercâmbio entre os diversos PPGs (Administração, Arquitetura, Design, Engenharia de Produção, etc), pois propicia uma forma de pensamento mais abrangente e pluralista, resultando um trabalho conjunto e uma troca rica de conhecimento. Corroborando esta visão, Couto e Marinho (2002) afirmam que essa falta de opções por estudos de pós-graduação na área de design no Brasil, em um primeiro momento, pode ser considerada uma fraqueza da área, mas também pode ser interpretada como uma oportunidade de crescimento e abertura de horizontes do design.

A partir da análise das teses e dissertações, corroborou-se o perfil multidisciplinar da Gestão de Design e do design como uma atividade multidisciplinar apoiada em conceitos de diversas áreas (BORJA DE MOZOTA, 2003, MINUZZI, PEREIRA, MERINO, 2003, MARTINS, 2004, LEMOS, 2006). Como fundamentação, três pontos mereceram destaque: a formação dos autores dos trabalhos, os 
programas de pós-graduação aos quais estes trabalhos estão vinculados e as palavras-chave utilizadas. Foram identificadas nos trabalhos palavras-chave (design, gestão de design, design de produto, projeto, gestão, competitividade, estratégia, moda) que remetem às áreas correlatas e envolvidas no estudo da gestão de design (Administração de Empresas, Engenharia da Produção, Design, Arquitetura e Artes). Outras palavras-chave encontradas nas teses e dissertações e presentes em debates atuais também denotam esta multidisciplinaridade, como 'qualidade', 'sustentabilidade', 'inovação' e 'custos', indicando relação direta com a gestão de design. A diversidade da formação dos autores também foi ponto de análise deste estudo, pois ao mesmo tempo em que o viés desta formação se mostra presente em alguns trabalhos, esta também propicia um intercâmbio de conceitos, experiências e reflexões, que nascem da união e das interfaces dessas áreas de estudo.

Observou-se também que, relacionando os estudos desenvolvidos nas teses e dissertações, muitos autores produziram artigos para congressos (MINUZZI, PEREIRA, MERINO, 2003, DICKIE, TORRES, MERINO, 2009, entre outros) e periódicos (AVENDAÑO, 2005, SILVA, FRANZOI, MERINO, 2008, entre outros). Isto é um ponto positivo, pois gera uma maior divulgação dos trabalhos e, consequentemente, uma maior troca e propagação de conhecimento, além da possibilidade de maior acesso a estas pesquisas.

Com relação aos setores de atividade estudados, acredita-se que a grande procura pelo ramo moveleiro se deve a crescente busca deste setor pelo uso e aplicação do design como diferencial competitivo. Além disso, o Brasil conta com grandes pólos moveleiros propícios ao estudo. De acordo com Libanio (2009), aliado a esses fatores, entende-se que as áreas do design, arquitetura e administração apresentam forte relação e entrosamento neste setor, criando um forte apelo para a realização de pesquisas voltadas para o ramo moveleiro. Outro setor bastante procurado para realização das pesquisas foi o têxtil e da moda. Percebe-se que este interesse deve-se ao fato deste setor apresentar grande dinamicidade e busca constante por design e inovação. Rybalowski (2008) destaca o design como um dos maiores formadores de valor do produto de vestuário e têxtil. Esses fatores propiciam um campo fértil para a disseminação dos conceitos e pesquisas acerca da gestão de design e temas correlatos. 
Quanto aos objetivos propostos nos trabalhos, grande parte destes busca compreender a gestão de design, sendo que alguns têm caráter estritamente teórico. Entretanto, algumas pesquisas como, por exemplo, SANTOS (2003), focam o estudo do design como um diferencial competitivo para as empresas sem, no entanto, considerar a gestão de design em sua totalidade. Assim, acabam abordando a Gestão de Design de maneira parcial, deixando de lado o estudo da parte estratégica da companhia. Outros trabalhos (MARTINS, 2004, CARDONETTI, 2009, FRANZOI, 2009, entre outros) se propõem a ir além, na tentativa de sistematizar a gestão de design nas organizações, propondo princípios, diretrizes ou até mesmo modelos de implementação. Todavia, o que se percebe, em alguns trabalhos (SILVA, 2003, PELEGRINI, 2005, entre outros), são proposições de metodologias baseadas em um estudo de caso (procedimento de pesquisa mais utilizado nos trabalhos pesquisados) e, por vezes, a serem seguidas por uma empresa em particular. Observa-se certa dificuldade na elaboração de um modelo mais abrangente, que seja aplicável a um número maior de organizações ou ainda que atinja um setor de maneira mais ampla.

Com relação ao papel do profissional de design, nota-se, por vezes, a falta de uma pesquisa aprofundada neste tópico. Acredita-se que o profissional de design seja um dos atores principais para o bom entendimento e adoção da gestão de design pelas empresas. Tanto o profissional de design quanto o gestor de design são peças-chave na Gestão de Design. Alguns trabalhos pesquisados (MEDEIROS, 1995, SILVA, 2003, entre outros) não evidenciam o papel deste profissional e sua importância para as organizações. No entanto, a formação do gestor de design fomenta discussões, já que, hoje em dia, poucos cursos de graduação em desenho industrial abordam a gestão de design em suas grades curriculares (Fascioni, 2008) e, consequentemente, não preparam o designer para assumir esta função. Avendaño (2003) questiona se o designer está apto a cumprir seu papel no atual contexto da sociedade e afirma que a gestão do design não precisa obrigatoriamente ser exercida por um desenhista industrial. Atualmente, muitos designers entram no mercado de trabalho com pouco ou nenhum conhecimento de ferramentas de gestão empresarial e acabam tendo que buscar este conhecimento em cursos de pós-graduação (Fascioni, 2008). Segundo a autora, somente $28 \%$ de todos os currículos de cursos de graduação em design do Brasil oferecem a 
disciplina de Gestão do Design. Ainda acrescenta que somente as Regiões Sudeste e Sul, em 2008, ofereciam cursos de pós-graduação em Gestão do Design no Brasil. O que se percebe é a carência de uma maior abordagem deste tema, já que, em graduações e pós-graduações brasileiras, destacam-se poucos trabalhos que apresentam uma abordagem consistente sobre o papel e as funções do gestor de design nas organizações.

Embora exista um crescente interesse de pesquisas na área em questão, a abordagem dada à gestão de design nas teses e dissertações pesquisadas, em diversos casos, ainda é parcial, focando o design como elemento para a melhoria da competitividade das empresas, mas deixando de lado toda a parte estratégica das organizações. Este tratamento acaba dando a gestão de design um caráter parcial, inconsistente e por vezes incompreensível, uma vez que não considera a totalidade da empresa nem aborda as diversas interações que a gestão de design defende. Muitos trabalhos não tratam ou não exploram em profundidade o papel do profissional de design e do gestor de design, o que fragiliza o entendimento de quais serão os atores responsáveis pelas ações e mudanças, e que papéis eles terão na empresa. Identifica-se a necessidade de um entendimento e maior aprofundamento das funções do gerente de projetos, do designer e do gestor de design, atores fundamentais para a gestão de design. Cabe ressaltar que empresas menores provavelmente não têm estrutura para suportar esses três cargos, e por isso devem dispor de uma clara descrição de funções dos profissionais envolvidos direta ou indiretamente em seus projetos. Os relatos sobre a realidade do mercado, a complexidade e a falta do entendimento de alguns conceitos mostram o grau de importância de se desenvolver estudos que realmente tratem da gestão de design em sua totalidade, possibilitando uma melhor compreensão desta pelas organizações, empresários e designers.

\section{CONCLUSÃO}

Este artigo apresentou uma revisão sistemática de literatura acadêmica acerca do tema gestão de design. Isto permitiu mapear a produção intelectual desenvolvida nos programas de pós-graduação brasileiros, publicadas nos últimos 
vinte anos, que abordassem o tema Gestão de Design, evidenciando oportunidades de pesquisa na área.

Baseado no conjunto de informações coletadas pôde-se concluir que a gestão de design é, cada vez mais, entendida de forma multidisciplinar, incentivando um intercâmbio de conhecimentos e reforçando uma visão pluralista. Entende-se ser positivo o desenvolvimento de estudos em diversas áreas de pesquisa, possibilitando uma melhor compreensão por parte de todos os sujeitos envolvidos nos setores da empresa e participantes da gestão de design. Assim, tanto designers quanto administradores poderão afinar seu entendimento acerca do tema em questão, integrando o trabalho entre as equipes e possibilitando que a gestão de design aconteça de fato nas empresas. As tentativas de desenvolvimento de princípios, diretrizes, modelos, metodologias, sistemáticas, programas e propostas são artifícios importantes para a melhor compreensão da implantação da gestão de design nas empresas e da relevância desta para empresários e profissionais de design. Para que a gestão de design seja implantada nas organizações, faz-se necessário o entendimento de 'como' fazer isto e quais os agentes que de fato estarão envolvidos neste processo. Feito isto, será possível que as empresas consigam tangibilizar os resultados advindos deste processo e que os sujeitos envolvidos visualizem como se posicionar frente às novas mudanças e desafios. Aliado a esses fatores, também será possível fomentar nas equipes de trabalho e nas áreas integrantes do processo a capacidade de constantemente trocar informações, trabalhando de maneira flexível e integrada e rompendo os antigos padrões.

A pesquisa realizada tem a limitação de ter sido aplicada em uma amostra de teses e dissertações brasileiras, não sendo possível aplicar os resultados e as conclusões obtidos em estudos internacionais sobre o tema. Em virtude disto, fica a sugestão de ampliar o leque de pesquisas futuras em estudos internacionais semelhantes.

É importante salientar a grande dificuldade ocorrida para a obtenção das teses e dissertações, seja pela indisponibilidade em meio virtual dos trabalhos mais antigos ou mesmo pela inexistência ou mau funcionamento de determinados sistemas virtuais de busca de teses e dissertações dos centros de pesquisa brasileiros. Entende-se ser necessário um incentivo para troca de conhecimento e 
maior volume de publicações em congressos e periódicos, já que os artigos, muitas vezes, têm mais facilidade de acesso do que teses e dissertações. Só assim, incentivando a propagação de um conhecimento gerado sob a ótica brasileira acerca da gestão de design, estudos desenvolvidos no Brasil conseguirão ir ao encontro das pesquisas e tendências globais sobre o tema.

\section{REFERÊNCIAS}

AVENDAÑO, Luis Emiliano Costa. Interação designer/empresa no contexto estratégico do desenvolvimento do produto. Dissertação (Mestrado) Universidade de São Paulo. São Paulo, 2003.

AVENDAÑO, Luis Emiliano Costa. Resgate do protagonismo do desenhista industrial por meio da gestão do design. Revista do Programa de Pós-Graduação em Arquitetura e Urbanismo da FAUUSP/USP, São Paulo, 2005.

BEST, Kathryn. Design Management: managing design strategy, process and implementation. Lausanne: AVA, 2006.

BIBLIOTECA DIGITAL brasileira de teses e dissertações do Instituto Brasileiro de Informação em Ciência e Tecnologia. Disponível em: <http://bdtd.ibict.br/> . Acesso em: 01 de ago. 2010.

BORJA DE MOZOTA, Brigitte. Design Management: Using Design to Build Brand Value and Corporate Innovation. New York: Allworth, 2003.

BRUCE, Margaret; COOPER, Rachel; VAZQUEZ, Delia. Effective design management for small businesses. Design Studies, 1999.

Centro Português de Design. Manual de gestão de design. Porto: Centro de Diseño, 1997.

CARDONETTI, Vivien Kelling. Princípios norteadores para a implementação e avaliação da gestão de design nas MPES do setor industrial de vestiário. Dissertação (Mestrado) - Universidade Federal de Santa Catarina. Florianópolis, 2009.

COUTO, Rita Maria de Souza, MARINHO, Priscilla Alvera Molaro. Pós-Graduação de designers brasileiros. Anais do P\&D Design, Rio de Janeiro, RJ, 2002.

DESIGN COUNCIL. Disponível em: <www.designcouncil.org.uk>. Acesso em: 12 ago. 2010.

DICKIE, I.B., TORRES, M.K.L., MERINO, E.A.D. Inovação social para o desenvolvimento sustentável: ação do óleo reciclado. ENCONTRO DE 
SUSTENTABILIDADE EM PROJETO DO VALE DO ITAJAÍ, 3. 2009. Anais... Itajaí, SC, 2009.

DMI - Design Management Institute. Disponível em: <www.dmi.org>. Acesso em: 08 ago. 2010.

FARR 1996 In: BORJA DE MOZOTA, Brigitte. Design management: using design to build brand value and corporate innovation. New York: Allworth, 2003.

FASCIONI, Ligia. Considerações sobre a formação dos gestores de design no Brasil. Anais do P\&D Design, São Paulo, SP, 2008.

FRANZOI, Luciana. Diretrizes para um programa de gestão de design com foco em produtos alimentícios de grupos produtivos familiares: a ótica do consumidor e do design. Dissertação (Mestrado) - Universidade Federal de Santa Catarina. Florianópolis, 2009.

GORB, Petter. Design management. New York: Van Nostrand Reinhold, 1990.

KISTMANN, Virginia Borges. A caracterização do design nacional em um mercado globalizado: uma abordagem com base na porcelana de mesa. Tese (Doutorado) - Universidade Federal de Santa Catarina. Florianópolis, 2001.

LIBÂNIO, Cláudia de Souza. Design como elemento estratégico para a melhoria da competitividade das empresas da cadeia moveleira de Bento Gonçalves, RS. Monografia (Especialização) - UniRitter. Porto Alegre, 2009.

MALDONADO, Tomás. El diseño industrial reconsiderado. Barcelona: Gustavo Gili, 1977.

MARTINS, Rosane Fonseca de Freitas. A Gestão de design como uma estratégia organizacional: um modelo de integração do design em organizações. Dissertação Mestrado) - Universidade Federal de Santa Catarina. Florianópolis, 2004.

McBRIDE, Mary. Design management: future forward. Design Management Review, n.18-3, 2007.

MINUZZI, R.F.B., PEREIRA, A.T.C., MERINO, E.A.D. Teoria e Prática na Gestão do Design. CONGRESSO INTERNACIONAL DE PESQUISA EM DESIGN, 2. 2003. Rio de Janeiro. Anais .... Rio de Janeiro: ANPED, 2003.

PORTAL DOMÍNIO PÚBLICO. Disponível em: <http://www.dominiopublico.gov.br/>. Acesso em: 01 ago. 2010.

RODRIGUES, Renato Buchele. A atividade de gestão do design nas organizações: um estudo no pólo moveleiro de Santa Catarina. Dissertação (Mestrado) - Universidade do Vale do Itajaí. Biguaçu, 2005. 
RYBALOWSKI, Tatiana Messer. A Gestão da diferenciação de produtos de moda: a inserção do artesanal na confecção industrial. Dissertação (Mestrado) PUCRJ. Rio de Janeiro, 2008.

SAMPAIO, R.F; MANCINI, M.C. Estudos de revisão sistemática: um guia para síntese criteriosa da evidência científica. Revista Brasileira de Fisioterapia, São Carlos, v.11, n.1, jan./fev. 2007.

SILVA, Luiz Sérgio Brasil D’Arinos. Gestão e design: uma abordagem estratégica ao desenvolvimento das organizações. Dissertação (Mestrado) - Universidade Federal do Rio de Janeiro. Rio de Janeiro, 2003.

SILVA, C.H., FRANZOI, L., MERINO, E.A.D. Alinhando as estratégias de design às estratégias da empresa por meio do balanced scorecard. Da Vinci. Curitiba, v.5, n.1, p. 97-110, 2008.

SPOLADORE, R., DEMARCHI, A. A gestão do design no desenvolvimento de produtos na indústria digital. Anais do P\&D Design, São Paulo, SP, 2004.

WOLF, Brigitte. 0 design management como fator de sucesso comercial. Florianópolis/SC: IEL, ABIPTI, Programa Catarinense de Design, SEBRAE, 1998.

WOLFF, F.; AMARAL, F. G. Toward a brazilian scale to measure performance by design management: two case studies. Proceedings of The International DMI Education Conference, Design Thinking: New Challenges for Designers, Managers and Organizations, France, 2008.

WOLFF, Fabiane. et al. Uma avaliação sistemática das publicações em gestão de design no Brasil. Anais do P\&D Design, São Paulo, SP, 2010.

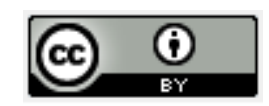

Artigo recebido em 24/11/2010 e aceito para publicação em 10/04/2011. 


\section{APÊNDICE A - Trabalhos considerados na análise dos dados}

[1] ANDRADE, Maurício Bergenthal de. Análise da Gestão de Projetos de Design nos Escritórios e Prestadores de Serviços em Design de Porto Alegre: Proposta Baseada em Estudos de Caso. Dissertação de Mestrado, Porto Alegre: UFRGS, 2009.

[2] AURIANI, Márcia. Gestão de Design nas indústrias de Calçados Femininos Jaú. Dissertação de Mestrado, São Paulo: UNIP, 2004.

[3] AVENDAÑO, Luis Emiliano Costa. Interação designer/empresa no contexto estratégico do desenvolvimento do produto. Dissertação de Mestrado, São Paulo: USP, 2003.

[4] BAARS, Edna Mara. A Gestão do Design no Contexto das Empresas e Órgãos de Fomento à Indústria de Santa Catarina. Dissertação de Mestrado, Florianópolis: UFSC, 2002.

[5] BENDER, Ana Regina. Inovação orientada pelo design estratégico: o caso da indústria de confecção de artigos do vestuário no Rio Grande do Sul. Dissertação de Mestrado, São Leopoldo: Unisinos, 2010.

[6] BERNARDO, Graziela Nicola. Gestão estratégica do design de embalagens: a comunicação visual a serviço da marca. Dissertação de Mestrado, São Paulo: USP, 2008.

[7] CABRAL, Glenda Gomes. Gestão de design em indústrias de produtos de uso: um estudo de caso da Companhia Industrial de Vidro - CIV. Dissertação de Mestrado, Recife: UFPE, 2008.

[8] CAMPOS, Maria Aparecida de Moraes. A pesquisa de tendências: uma orientação estratégica no design de jóias. Dissertação de Mestrado, Rio de Janeiro: PUCRJ, 2007.

[9] CARDONETTI, Vivien Kelling. Princípios norteadores para a implementação e avaliação da gestão de design nas MPES do setor industrial de vestiário. Dissertação de Mestrado, Florianópolis: UFSC, 2009.

[10] CARDOZO, Marcos Antonio. Modularização e design: um estudo de caso sobre o cockpit do modelo Fox da Volkswagen do Brasil. Dissertação de Mestrado, Curitiba: UFPR, 2005.

[11] CARNIATTO, Izamara Vanessa. Gestão de design e artesanato: uma abordagem com base na pesquisa-ação. Dissertação de Mestrado, Curitiba: UFPR, 2008.

[12] CASTEIÃO, André Luiz. A Gestão de Design como Diferencial Competitivo em microempresas do Setor Moveleiro. Dissertação de Mestrado, Bauru: UNESP, 2006.

[13] CASTRO, Maria Luiza Almeida Cunha. Direcionamentos estratégicos sustentáveis de design para o setor moveleiro em contexto de arranjos produtivos locais: os casos de Amapá (AP) e Ubá (MG). Tese de Doutorado, Belém: UFPA, 2009.

[14] CRUZ, Karen Rejane Viana Abs da. Aplicação de Design Estratégico no Pólo Joalheiro de Guaporé. Dissertação de Mestrado, São Leopoldo: Unisinos, 2010.

[15] DAMIN, Vânia Maria. Elementos sobre o processo de Construção do briefing. O caso Saccaro. Dissertação de Mestrado, São Leopoldo: Unisinos, 2010. [16] DEL PUPPO, Jaquelini Loureiro. O processo de gestão do design no arranjo produtivo do vestuário de Colatina: uma investigação a partir do capital social. Dissertação de Mestrado, Vitória: UFESP, 2006. 
[17] DICKIE, Isadora Burmeister. Gestão de design aplicada: estratégias de comunicação no contexto do design sustentável. Dissertação de Mestrado, Florianópolis: UFSC, 2010.

[18] EMIDIO, Lucimar de Fátima Bilmaia. A gestão do design como estratégia de desenvolvimento para MPES do vestuário de moda: um estudo de caso na região de Londrina. Dissertação de Mestrado, Baurú: UNESP, 2006.

[19] FERREIRA, Alexandre Rodrigues. A utilização do design na gestão da qualidade: uma mudança de paradigmas no setor moveleiro de Santa Maria - RS. Dissertação de Mestrado, Santa Maria: UFSM, 2008.

[20] FERREIRA, Eliza. O design como estratégia de inovação para a competitividade e sustentabilidade de países, empresas e comunidades: o caso Ipameri - GO. Dissertação de Mestrado, Brasília: UNB, 2006.

[21] FORNASIER, Cleuza Bittencourt Ribas. Modelo organizacional de autogestão para projetos sociais: uma ação de design. Dissertação de Mestrado, Florianópolis: UFSC, 2005.

[22] FRANZOI, Luciana. Diretrizes para um programa de gestão de design com foco em produtos alimentícios de grupos produtivos familiares: a ótica do consumidor e do design. Dissertação de Mestrado, Florianópolis: UFSC, 2009.

[23] FREIRE, Anderson. Avaliação da gestão para inovação nas empresas de design no Brasil. Dissertação de Mestrado, Rio de Janeiro: ESDI/UERG, 20010.

[24] FREITAS, Luciana Costa de. Estratégias de design em empreendimentos de moda: As tramas do sucesso empresarial no design de moda da cidade do Rio de Janeiro. Dissertação de Mestrado, Rio de Janeiro: PUCRJ, 2007.

[25] GALLINA, Marcelo Catto. Ações do líder na gestão design como auxílio na formação do branding: um estudo de caso em uma empresa do setor do mobiliário. Dissertação de Mestrado, Curitiba: UFPR, 2006.

[26] GOMES, Paola Albiero. O Design como diferencial competitivo para alavancar as exportações das pequenas e médias empresas do setor moveleiro. Dissertação de Mestrado, Curitiba: PUCPR, 2005.

[27] GONÇALVES, Camila de Oliveira. A comunicação entre o design e o departamento produtivo de uma confecção de vestuário: um caso no segmento de surfwear. Dissertação de Mestrado, Santos: UNISANTOS, 2008.

[28] JAYME, Maria Emília Mendes. Tendências: recomendações para seu uso na gestão do design das MPEs produtoras de louça de mesa de Campo Largo - PR. Dissertação de Mestrado, Curitiba: UFPR, 2009.

[29] KAMPMANN, Mariana. O ergodesign como diferencial competitivo no processo de gestão de design de uma PME fabricante de mobiliário para escritório: o caso Flexiv. Dissertação de Mestrado, Curitiba: CEFET/PR, 2003.

[30] KELLER, Jacqueline. A gestão do design na moda: processos que agregam valor e diferencial ao produto de moda. Dissertação de Mestrado, Florianópolis: UFSC, 2004.

[31] KISTMANN, Virginia B. A caracterização do design nacional em um mercado globalizado: uma abordagem com base na porcelana de mesa. Tese de Doutorado, Florianópolis: UFSC, 2001.

[32] LEMOS, Roselie de Faria. A inserção do design em indústrias de utensílios domésticos dos estados de Santa Catarina e Rio Grande do Sul. Dissertação de Mestrado, Blumenau: FURB, 2006. 
[33] MAGALHÃES, Cláudio Freitas de. Design Estratégico: integração e ação do design industrial dentro das empresas. Dissertação de Mestrado, Rio de Janeiro: UFRJ, 1994.

[34] MAGALHÃES, Cláudio Freitas de. A influência do processo de especificação de produtos para a eficácia dos projetos. Tese de Doutorado, Rio de Janeiro: UFRJ, 2003.

[35] MARTINS, Marco Aurélio Veiga. A gestão do design no segmento de eletrodomésticos de linha branca. Dissertação de Mestrado, Rio de Janeiro: UFRJ, 2004.

[36] MARTINS, Rosane Fonseca de Freitas. A gestão de design como uma estratégia organizacional: um modelo de integração do design em organizações. Tese de Doutorado, Florianópolis: UFSC, 2004.

[37] MEDEIROS, Estevão Neiva de. Análise de Aspectos do Gerenciamento do Design de Produtos em Processos de Modernização Tecnológica, sob um Enfoque Ergonômico. Tese de Doutorado, Rio de Janeiro: UFRJ, 2005.

[38] MELLO, Tatiana Schoneweg. Aspectos relativos à promoção do design no Brasil visando a área da gestão: o caso da empresa vencedora do Prêmio CNI José Mindlin 2000. Dissertação de Mestrado, Florianópolis: UFSC, 2003.

[39] MERINO, Giselle Schmidt Alves Díaz. Contribuição da gestão de design em grupos produtivos de pequeno porte no setor da maricultura: o caso Amprosul. Dissertação de Mestrado, Florianópolis: UFSC, 2010.

[40] MINUZZI, Reinilda de Fátima Berguenmayer. A formação do designer de superfície na UFSM e a atuação do designer em empresa cerâmica de SC no contexto da gestão do design. Dissertação de Mestrado, Florianópolis: UFSC, 2001.

[41] MINUZZI, Reinilda de Fátima Berguenmayer. Modelo de um núcleo virtual de estudos colaborativos em gestão de design. Tese de Doutorado, Florianópolis: UFSC, 2006.

[42] MORAES, Márcia Bergmann. O impacto do design no desempenho de empresas da indústria eletroeletrônica brasileira. Dissertação de Mestrado, Rio de Janeiro: PUCRJ, 2007.

[43] MOURA, Janine Barbosa. Gestão de Design: uma análise quantitativa em empresas brasileiras listadas no ranking IF design. Dissertação de Mestrado, São Leopoldo: Unisinos, 2009.

[44] NASCIMENTO, Marilzete Basso. A incorporação do design por uma indústria moveleira voltada ao seguimento popular: um estudo de caso no pólo moveleiro de Arapongas - PR. Dissertação de Mestrado, Florianópolis: UFSC, 2001. [45] OLIVEIRA, Romeu Dâmaso de. Design Industrial e Empresa de Pequeno Porte: Interações, Benefícios e Estratégias. Dissertação de Mestrado, Belo Horizonte: UFMG, 2000.

[46] PELEGRINI, Alexandre Vieira. O processo de modularização em embalagens orientado para a customização em massa: uma contribuição para a gestão do design. Dissertação de Mestrado, Curitiba: UFPR, 2005.

[47] PEREIRA, Delcio. Competências da Gestão Estratégica do Design no Pólo Moveleiro do Alto Vale do Rio Negro (SC). Dissertação de Mestrado, Ponta Grossa: UTFPR, 2009.

[48] RAMOS, Carlos Fabian Reinoso. Importância do design nas empresas sob o enfoque estratégico: estudo de caso nas indústrias de móveis para escritório. Dissertação de Mestrado, Rio de Janeiro: UFRJ, 1996. 
[49] RIVA, Josiane Lazaroto. A interação entre as áreas de design e marketing para o sucesso de projetos inovadores de embalagens. Dissertação de Mestrado, Florianópolis: UFSC, 2001.

[50] RODRIGUES, Renato Buchele. A atividade de gestão do design nas organizações: um estudo no pólo moveleiro de Santa Catarina. Dissertação de Mestrado, Biguaçu: Universidade do Vale do Itajaí, 2005.

[51] RYBALOWSKI, Tatiana Messer. A Gestão da diferenciação de produtos de moda: a inserção do artesanal na confecção industrial. Dissertação de Mestrado, Rio de Janeiro: PUCRJ, 2008.

[52] RUIZ, Eugênio Weishaupt. $O$ design no marketing de produtos: um estudo exploratório na indústria eletro-eletrônica brasileira. Dissertação de Mestrado, São Paulo: USP, 1999.

[53] SANTOS, Luis Cláudio Belmonte dos. Subsídios para gestão de design na indústria moveleira. Dissertação de Mestrado, Rio de Janeiro: UFRJ, 2003.

[54] SANTOS, Suely Xavier dos. Inserção do design em micro e pequenas empresas: o caso de duas indústrias moveleiras no Estado do Rio Grande do Norte. Dissertação de Mestrado, Natal: UFRN, 2007.

[55] SELEME, Eliane Betazzi Bizerril. Design um fator estratégico para a competitividade da indústria moveleira. Dissertação de Mestrado, Florianópolis: UFSC, 2002.

[56] SHUL, Geane Cristina. O design como diferencial competitivo: um estudo em pequenas empresas calçadistas do Vale do Sinos. Dissertação de Mestrado, São Leopoldo: Unisinos, 2006.

[57] SILVA, Alice Maria Ribeiro da. O uso do grés no design cerâmico de embalagens para cosméticos. Dissertação de Mestrado, Curitiba: UFPR, 2008.

[58] SILVA, Cláudio Henrique da. Balanced scorecard como ferramenta para gestão estratégica de design. Dissertação de Mestrado, Florianópolis: UFSC, 2009.

[59] SILVA, Luiz Sérgio Brasil D’Arinos. Gestão e Design: uma abordagem estratégica ao desenvolvimento das organizações. Dissertação de Mestrado, Rio de Janeiro: UFRJ, 2003.

[60] SILVA, Sandra de Brito da. As forças da gestão do design nos níveis estratégico, tático e operacional: um estudo de caso na Electrolux do Brasil S.A. Dissertação de Mestrado, Curitiba: UFPR, 2009.

[61] SOUZA, Cleone Ferreira de. A inserção do design como fator gerador de diferencial competitivo para as micro e pequenas empresas calçadistas da Paraíba. Dissertação de Mestrado, João Pessoa: UFPB, 2006.

[62] TEIXEIRA, Joselena de Almeida. O design estratégico na melhoria da competitividade das empresas. Tese de Doutorado, Florianópolis: UFSC, 2005.

[63] VIEIRA, Irineu Cezar. Competitividade Através da Gestão do Design: Um Estudo dos Fatores Críticos de Sucesso no Processo de Desenvolvimento de Produtos em Empresas no Setor Médico-Odonto-Hospitalar e Laboratorial. Dissertação de Mestrado, Belo Horizonte: UFMG, 2002. 